\title{
Who killed the English National Health Service?
}

\author{
Martin Powell*
}

Abstract

The death of the English National Health Service (NHS) has been pronounced many times over the years, but the time and cause of death and the murder weapon remains to be fully established. This article reviews some of these claims, and asks for clearer criteria and evidence to be presented.

Keywords: English National Health Service (NHS), End of the NHS, Criteria

Copyright: $\odot 2015$ by Kerman University of Medical Sciences

Citation: Powell M. Who killed the English National Health Service? Int J Health Policy Manag 2015; 4: 267-269. doi: $10.15171 /$ ijhpm.2015.72

\section{Article History: \\ Received: 25 February 2015 Accepted: 19 March 2015 ePublished: 23 March 2015 \\ *Correspondence to: \\ Martin Powell \\ Email: m.powell@bham.ac.uk}

\section{Introduction}

Who killed the English National Health Service (NHS)? Mixing the film 'Casablanca' with the board game 'Cluedo', let us 'round up the usual suspects'. Was it Mrs. Thatcher with the weapon of competition from 'Working for Patients' (1)? Colonel Milburn using 'Foundation Trusts'? Dr. Reid with a full healthcare market of the 'NHS Improvement Plan' (2)? Or Rev Lansley changing the role of the Secretary of State in the Health and Social Care Act (HSCA) of 2012?

The death of the NHS has been pronounced many times over the years, but the time and cause of death and the murder weapon remains to be fully established. This is because the criterion is often implicit, unclear or contestable. Is it linked to principles, values, objectives, institutional form, inputs, outputs, or outcomes? Is the template of evaluation intrinsic or extrinsic criteria, temporal changes, or international comparisons? In other words, in a reverse alchemy process, what is the anti-philosopher's stone which changes the gold of the NHS into baseless metal.

The exaggerated accounts of the death of the National Health Service (NHS)

The headlines of some UK newspapers from January $7^{\text {th }}$ 2015 state that the 'NHS hits breaking point' ('i'), the 'NHS is dying' (Daily Mirror), is 'in meltdown' (Daily Express), and is like something from the third world' (Sun). In more detail, according to the 'Daily Mirror', our NHS is dying as hospitals go into meltdown with the worst waiting times in a decade. A beleaguered NHS is on the brink of disaster, is teetering on the edge, at a tipping point, and in crisis.

However, it can almost be said that some commentators have claimed that the NHS has been in crisis at some point in each of its 67 years of its existence, and - like Mark Twain accounts of its death have been exaggerated. Let us start with Aneurin Bevan, the Labour Minister of Health who founded the NHS. Bevan (3) wrote that new legislation on the NHS has been announced, which 'confirms our worst fears', and if carried through, will 'mutilate the service in many of its most important activities'. A number of commentators have argued that the Conservative White Paper 'Working for Patients' (1) which introduced the 'internal market' could lead to the end of the NHS. For example, Labour Shadow Health Secretary, Robin Cook, argued that the government was taking 'a succession of Granny's footsteps tiptoeing away from a universal, publicly-provided comprehensive health service hoping that no one will be sufficiently alarmed by the noise to ask the questions of principle raised by each step' (4). Similarly, according to Stephen Lock, the Editor of the BMJ, 'it is not fanciful to talk about the end of the traditional health service ... its decent principle of uniform access to a high standard of medical care' (4).

In the run-up to the 1997 General Election, the Labour Party claimed variously that there were 7 days or 24 hours to save the NHS. As their 1997 Manifesto put it, if the Conservatives are elected again there may well not be an NHS in five years' time - neither national nor comprehensive'.

Pollock (5) pointed to the HSCA 2001, and argued that 'unless the legislation is amended, Bevan's legacy and the principles of universality and comprehensive care upon which the NHS was founded will be destroyed, and the Health and Social Care Bill will indeed be the last act of the NHS'. Pollock (6) pointed to two further possible tipping points. First, she argued that if the 1962 Hospital Plan was the high point in the evolution of the NHS, the introduction of 'Foundation Trust' hospital (hybrid public-private-mutual institutions with a significant degree of autonomy) marked its virtual demise (p. 130). Second, she claimed that in June 2004 the government finally confirmed that the NHS as a democratically accountable public service was to be replaced by a full healthcare market, with New Labour's death sentence on Attlee's and Bevan's NHS pronounced by the Health Secretary John Reid, in a statement announcing publication of the 'privatisation plan', the 'NHS Improvement Plan' (2) (p. 237-8).

Contributors to 'NHS SOS' (7) suggested yet more death sentences. According to John Lister, it could be said that the NHS as we know it was abolished in April 2013 (by the HSCA) (p. 17). Jacky Davis and David Wrigley claimed that the HCSA completed the transformation of the NHS into 
a fully fledged market' (p. 119). Oliver Huitson argued that the HCSA formally removed the Secretary of State's 'duty to provide comprehensive healthcare' - the legal foundation of the NHS since 1948- leaving only a duty to 'promote' (p. 168). Allyson Pollock pinpointed the demise of the NHS: at 2.36 PM 27 March 2012 the HSCA, repealing the legal foundations of the NHS in England, was given royal assent and became law, which marked the end of a NHS in England (p. 174-5)

In January 2015, the Labour Party (8) stated that the NHS as you know it cannot survive five more years of David Cameron, pointing to deteriorating service standards, that are already breaching the NHS Constitution guarantees; Tory plans to reduce the overall level of spending on public services to levels not seen since the 1930s; and ever greater competition and privatisation. It concluded that 'based on the past five years, if the Tories are allowed to carry on as they have been, another Tory term in power would make the NHS unrecognisable'.

All this leaves a rather confusing picture. The criteria of the end of the NHS appear to include breaching the principles of the NHS (e.g. comprehensive, universal, equal, free at the point of use) $(4,6,7,9)$, competition and privatisation $(6,7,10)$, and changing the duty of the Secretary of State (7). There is problem of detecting a clear 'tipping point' of a breach of principle, partly because of the problem of selecting and operationalising the principles of the NHS and partly because it can be argued that principles have always been imperfectly realised in practice $(4,9)$. For example, Ruane (10) focuses on collectivism of funding and the production of healthcare, accompanied by planning and based on the devalorization of labour, as the central features of the NHS in 1948 rather than focusing on principles such as comprehensiveness and universality. It can be argued that the free at the point of use' principle is the easiest to understand, and may have the greatest resonance with the public. While the NHS has seen charges for some services for many years for certain groups, these have - so far - not been applied to General Practitioner (GP) or hospital visits. Issues such as surplus value, valourisation, and de-commodified labour (10) may be more difficult to 'sell' to the public. Ruane (10) criticises the 'top-down policy initiatives approach' preferring to focus on the 'analysis of the culture of the organization and the actors within it', but such an approach would preclude pointing to the HCSA.

Similarly, the time of its demise remains unclear. It has been associated with specific documents such as White Papers or Acts of Parliament $(6,7)$. It has also been associated with periods. Pollock (6) points out that after 1979 the emerging health service - no longer comprehensive, universal or free - moved away from being a right, back towards being a commodity - as it had been before 1948 (p. 34-5), but also that for more than 50 years [i.e. after 1998] the NHS delivered high-quality care on the basis of need to most patients most of the time (p. 234). Of course, policies interact with each other in complex forms of layering (10), but pointing to policy evolution masks more precise pivotal mechanisms. Moreover, some commentators argue that the template of 'Bevan's NHS' (comprehensive, universal, free) is difficult to sustain given technological push, demographic pull and the 'tsunami' of austerity, but this is dismissed by the 'sustainability deniers' [see Taylor 2013: Chapter 3 (11)].
Moving to a wider comparative perspective, if missed targets for A\&E waits in England pointed to a NHS on the 'brink of disaster', teetering on the edge, at a tipping point, and in crisis (Daily Mirror), then waits in Wales and Northern Ireland that missed their targets by greater margins (77\% and $81 \%$ respectively) (12) must constitute a greater crisis. Moreover, the positive evaluation by the Commonwealth Fund (13) which placed the UK best of 11 countries on overall rank and for 9 of 11 criteria do not suggest a dying NHS. However, the data relates to 2011-3, and it is possible that a future ranking may show a sharp decline.

\section{Crying wolf at the cat with nine lives}

Minister of Health, Simon Burns (14) claims that every major change to the NHS has been caricatured as a relentless march towards the end of free healthcare. He points out that Allyson Pollock used very similar words for the very different Health and Social Care Bills of 1999 and 2012. He claims that such accusations have become political grenades carelessly and indiscriminately lobbed at anything that looks like change. The NHS's history is peppered by their deployment, and they have been so overused over the past few decades, they have become rather meaningless. He concludes (optimistically and with too much complacency) that after nearly three decades of doomsaying, what do we have? An NHS that still provides a universal service, free at the point of use, and is as far removed from a U.S-style insurance system as any other health service on the planet.

Accounts of the death of the NHS have been exaggerated. The NHS appears to be like the proverbial cat with nine lives, or a complex TV mystery drama where an assailant stabs a corpse killed earlier by a shot to the heart. This is not an argument for complacency but simply a request for clarity. Repealing the HSCA (8) and to reinstate the duty of the Secretary of State (7) would wind the clock back to about 2010, when the NHS had already ended by some accounts $(6,7)$. Moreover, it is difficult to see how a change in words can end the NHS as, according to some of the same commentators, it had already been ended while the previous stronger 'duty' (to 'provide' rather than to 'promote') was in existence.

Finally, the 'weapon' remains unclear. Is it policy intentions (for example in White Papers), which can be modified as Parliamentary Acts, or is it the way in which these Acts are implemented? What is the balance between 'structure' and 'agency' [e.g. the 'culture of the NHS'; see e.g. Taylor (11)]? Just because something can happen does not ensure that it does happen. For example, 'thin end of wedge' arguments that Foundation Trusts can pave the way for privatisation can also be applied to GPs (primary care physicians) as independent contractors since 1948. So what is needed to revive the NHS? Removing Foundation Trusts, or all competition and privatisation? More funding? A return to the 1948 model? It is unhelpful to 'cry wolf' that every change to the NHS will lead to its end. It is possible that the wolf is now at the door of the NHS, but alarmed cries may no longer be heeded.

Ethical issues

Not applicable.

Competing interests

Author declares that he has no competing interests. 
Author's contribution

MP is the single author of the manuscript

\section{References}

1. Department of Health. Working for Patients. London: The Stationery Office; 1989.

2. Department of Health. The NHS Improvement Plan. London: The Stationery Office; 2004.

3. Bevan A. In Place of Fear (first published 1952). London: Quartet; 1978

4. Powell M. Granny's footsteps, fractures and the principles of the NHS. Critical Social Policy 1996; 16: 27-44.

5. Pollock A. Will primary care trusts lead to US-style health care? Br Med J 2001; 322: 964-7.

6. Pollock A. NHS Plc: The Privatisation of our Health Care. London: Verso; 2005.

7. Davis J, Tallis R. NHS SOS. London: Oneworld; 2013.

8. Labour Party. The NHS as you know it cannot survive five more years of David Cameron [internet]. 3 January 2015. Available from: http://press.labour.org.uk/post/107042028464/the-nhs-asyou-know-it-cannot-survive-five-more

9. Powell M. Evaluating the National Health Service. Buckingham: Open University Press; 1997.

10. Ruane S. Public-private boundaries and the transformation of the NHS. Critical Social Policy 1997; 17: 53-78.

11. Taylor R. God Bless the NHS. London: Faber and Faber; 2013.

12. BBC News. Wales and NI A\&E waits 'worsen', N. Triggle, 16 January 2015. Available from: http://www.bbc.co.uk/news/ health-30847730

13. Davis K, Stremikis K, Squires D, Schoen C. Mirror, Mirror on the Wall, How the Performance of the U.S. Health Care System Compares Internationally [internet]. New York: Commonwealth Fund; 2014. Available from: http://www.commonwealthfund.org/ publications/fund-reports/2014/jun/mirror-mirror

14. Department of Health. Simon Burns: Why any change to the NHS is always opposed; 14 March 2012. 